\title{
Paisaje cultural lechero, cuestión de identidad
}

\author{
Reflexiones sobre identidad en el paisaje lechero \\ del norte de Antioquia
}

\author{
Julián Monsalve Correa*
}

Citar este artículo como: Monsalve Correa, J. Paisaje cultural lechero, cuestión de identidad. Reflexiones sobre identidad en el paisaje lechero del norte de Antioquia. Revista nodo, 12(22). Bogotá, 2017, pp. 68-81

\section{Resumen}

El ser humano transforma el paisaje natural, y a su vez el paisaje condiciona la identidad de quienes lo habitan. La relación recíproca y constante entre ser humano y paisaje ha sido reconocida reiteradamente y expuesta de manera clara y sintética en Landscape Character Assesment (Swanwick, 2002). La resultante de tal dinámica, son los paisajes culturales en constante transformación y diversos grados de antropización. La inquietud conceptual surgida al observar este hecho origina el presente artículo de índole reflexiva, aplicado a un territorio conocido y sentido por el autor, quien de esta manera inicia un proceso investigativo al respecto.

El paisaje lechero de tierra fría en el norte de Antioquia es un ejemplo de paisaje cultural con intensa vocación productiva y reconocidos atractivos visuales, que se han consolidado en la medida en que la población campesina que lo habita ha transformado el bosque andino en un mosaico paisajístico de pastos, cultivos y cuerpos de agua, de acuerdo a las necesidades de cada momento histórico. En este escrito se propone una revisión de dicho paisaje cultural, a la luz del estado de conservación de su estructura natural, y de la forma en que ésta es percibida y valorada, como primer paso hacia la construcción de una relación armoniosa entre el paisaje y quienes lo habitan.

Desde el enfoque paisajista, se proponen el reconocimiento de los valores significativos del paisaje lechero, y principalmente el análisis y registro de lo que ese paisaje representa para sus habitantes y visitantes. Se trata de reconocer las diversas maneras como la gente se identifica con su paisaje, escudriñando las representaciones e imaginarios subconscientes, en ese vínculo intangible, que va más allá del simple beneficio económico de subsistencia.

Este trabajo expone las reflexiones iniciales desarrolladas por el autor en el primer año de la Maestría en Diseño del Paisaje, en los cursos: Paisaje Local, Teoría e Historia del Paisaje y Recurso Visual. Algunas imágenes que ilustran el artículo son producto del trabajo de campo y la observación permanente del paisaje lechero entre 2008 y 2016. El conjunto de textos e imágenes constituyen una reflexión que precede a la formulación de una investigación sobre Paisaje Cultural Lechero propuesta por el autor como trabajo de grado.

Palabras clave: Paisaje cultural, identidad paisajista, valoración paisajista, paisaje lechero.

Fecha de recepción: 12 julio de 2016 • Fecha de aceptación: 5 de junio 2017

* Arquitecto, Universidad Nacional de Colombia, Sede Medellín. Docente de las Facultades de Diseño Industrial y de Diseño de Vestuario, Universidad Pontificia Bolivariana. Estudiante de la Maestría en Diseño del Paisaje de la Universidad Pontificia Bolivariana Medellín. 


\section{Abstract}

The human being transforms the natural landscape, and landscape shapes the identity of those who inhabit it. The result of this dynamic are cultural landscapes, in constant transformation, with varying degrees of anthropization.

The dairy production landscape in the cold highlands of north Antioquia is an example of a cultural landscape. The intense productive vocation and strong visual elements in this landscape have been possible due to the rural population who transformed the Andean forest into a fragmented mosaic of pastures, food plantations, water bodies and non-productive spaces, according to the needs of each historical moment.

This paper proposes a revision of this cultural landscape, based on fieldwork and permanent observation. It focuses on the significant values and social perceptions of the landscape and its natural structure. Furthermore, the article recognizes different constructions of identity within the landscape, scrutinizing subconscious representations beyond economic profit.

The texts and images are result of the landscape experience of the author. They precedes the formulation of an investigation about cultural landscapes of dairy production in north Antioquia developed the Master of Landscape Design at UPB, Medellín, Colombia.

Keywords: Cultural landscape, landscape identity, landscape character, rural landscape.

\section{Introducción. El paisaje cultural y su transformación permanente}

De acuerdo con la UNESCO, los paisajes culturales son bienes que representan las "obras conjuntas del hombre y la naturaleza” (UNESCO, 2005). Los paisajes culturales ilustran la evolución de la sociedad humana y sus asentamientos a lo largo del tiempo, condicionados por las limitaciones y/u oportunidades físicas que ofrece el entorno natural y por las sucesivas adaptaciones o adecuaciones provenientes de las fuerzas sociales, económicas y culturales, tanto externas como internas que inciden en la transformación constante.

Esta amplia definición da pie a la aplicación del concepto paisaje cultural a situaciones de paisajes locales, cotidianos, rurales e inclusive degradados; es decir, a aquellas tipologías que carecen de un valor patrimonial excepcional y universal, pero que guardan un alto significado para quienes habitan cada región. Una mirada paisajista puede contribuir a la comprensión de la responsabilidad de los habitantes en la construcción de un paisaje particular que por ende refuerza su propia identidad. Colombia, ha sido reconocida por su Paisaje Cultural Cafetero, un paisaje cultural productivo en permanente desarrollo (Ministerio de Cultura, 2010); no obstante, dentro de la amplia diversidad que caracteriza al país, bien cabe analizar y aprender de la multiplicidad de paisajes culturales asociados a contextos productivos que alberga cada una de sus diversas regiones biogeográficas.

La relación entre un paisaje cultural y las personas que lo habitan tiene un carácter interactivo, es una construcción de ida y vuelta. Las personas construyen el paisaje de acuerdo con sus valores, inspiraciones y motivaciones. A su vez el paisaje construye y moldea las personas que lo habitan, su identidad y sus hábitos, de acuerdo con los valores implícitos en cada lugar. El ser humano, produce paisajes, al volcar en ellos sus valores. Las necesidades, aspiraciones, anhelos, experiencias propias $y$ ajenas pueden leerse tanto en las personas como en los paisajes que habitan (Aponte, 2003).

Por otra parte, el paisaje es una construcción intergeneracional, es producto de la superposición de transformaciones en diferentes momentos históricos. El paisaje es lo que la gente hace de su entorno, después de que la naturaleza lo ha puesto en sus manos (Appleton, 1986); es producto de las sucesivas transformaciones culturales efectuadas, a partir de una base natural, por todas las generaciones que lo han habitado. Una generación recibe el paisaje natural, lo transforma y lo entrega 


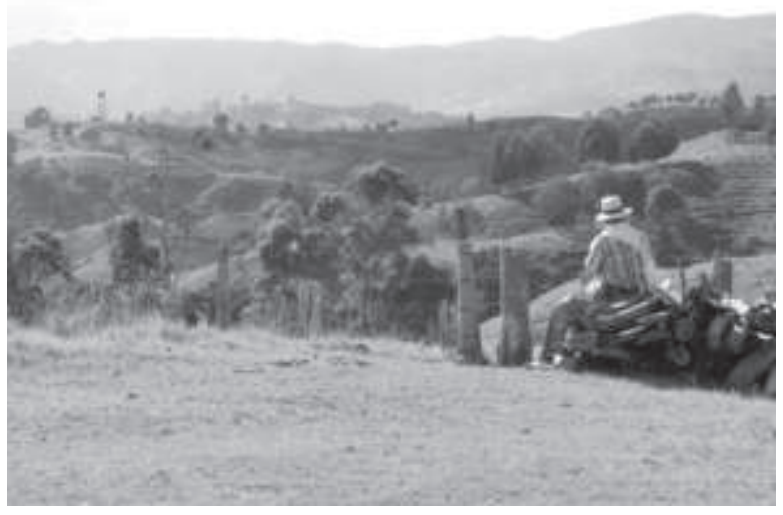

Figura 1. Colinas cubiertas de pastos abiertos, árboles dispersos y construcciones dispersas. El sistema montañoso en el plano de fondo se extiende hasta el Páramo de Belmira. Fuente: Archivo del autor.

a la siguiente, junto con los valores acumulados en el tiempo y las sucesivas transformaciones que realiza sobre éste. En la transformación permanente, la base natural deja de ser dominante en el territorio y se convierte en un aspecto cada vez más subordinado, se torna menos visible y menos reconocible. El ecosistema primigenio sobre el cual se han construido los paisajes culturales, comienza a desdibujarse a raíz de las operaciones efectuadas en el lugar por las sucesivas generaciones, desarrolladas en condiciones de vida y contextos históricos bien diferentes.

\section{Paisaje lechero de tierra fría en el norte de Antioquia}

'Ese pedazo'e monte está bueno pa' tumbalo $y$ ponelo a cargar ganao"

Mayordomo de finca en la Vega del Río Grande, Santa Rosa de Osos.

Un caso particular, en el sentido de esa construcción sucesiva del paisaje, es el que se registra a partir de la producción lechera del norte de Antioquia, consolidado sobre la región geográfica de San Pedro de los Milagros, Entrerríos, Santa Rosa de Osos, Don Matías y Yarumal donde se han asen-

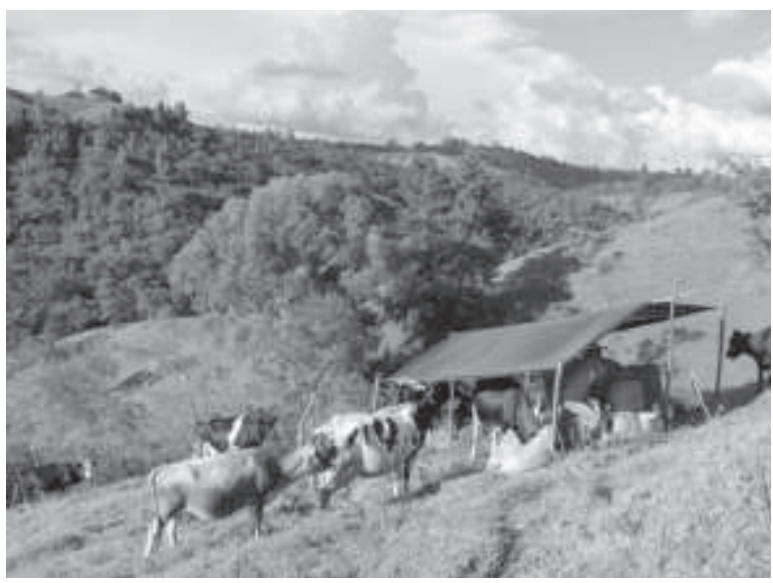

Figura 2. Ordeñaderos en el paisaje lechero del Río Grande, Santa Rosa de Osos. Fuente: Archivo del autor.

tado desde la década de 1960 las mayores industrias lecheras de Antioquia (Colanta, 2017). Tal vez el término paisaje cultural lechero antioqueño no se ha puesto en uso hasta el día de hoy en la región. Sin embargo, al hacer referencia al término paisaje lechero es posible que se hagan asociaciones con el término ruta lechera, un nombre mucho más popular y cotidiano, con el cual se reconoce el recorrido por los paisajes de la región.

Desde la mirada paisajera (Berque, 2009) es posible hablar de un paisaje lechero, pues se trata de la expresión de un lugar con una imponente matriz compuesta por pastos para ganadería de tierra fría con algunos parches de plantaciones forestales, cuerpos de agua, relictos de bosque andino y por supuesto, la presencia importante de una población conformada por familias campesinas, dedicada a la crianza de ganado de leche como actividad económica principal.

Según Espinal, este paisaje de colinas ondulantes, localizado por encima de los 2000 metros se encuentra en la zona de vida BH-MB, Bosque Húmedo Montano Bajo (Espinal, 1992) y asciende casi hasta el ecosistema de páramo cerca de los 3000 metros en el Páramo de Belmira. Socialmente se ha aceptado este paisaje como una de las numerosas tipologías de paisaje antioqueño; así como se habla, por ejemplo, de suroeste antioqueño para 
hacer referencia al paisaje cafetero de la región donde se asientan municipios productores de café como Jardín, Jericó y Ciudad Bolívar. En tanto el viajero acude al paisaje cafetero en busca del clima templado, los cafetales y la pintoresca arquitectura de la colonización antioqueña, en el lugar de estudio persigue la experiencia de un paisaje de clima frío, de potentes visuales que se extienden a través de las colinas ondulantes cubiertas por pastos siempre verdes donde se cría ganado lechero Holstein y Jersey. Esta ruta, que se hizo posible gracias a los proyectos de conexión vial entre la región norte y el valle de Aburrá, desde la década de 1970, tiene como puntos de referencia los paradores y las queseras donde el viajero encuentra quesitos, pandequesos y otros alimentos tradicionales fabricados con leche de la región.

Una parte importante de la población antioqueña, particularmente la residente en el valle de Aburrá, percibe las características naturales y culturales, apreciables en la ruta lechera, como un conjunto, como una gran zona homogénea de paisaje. A lo largo del circuito paisajístico Medellín -Entrerríos con retorno por Santa Rosa de Osos y Don Matías hacia el norte del valle de Aburrá se da cierta uniformidad y coherencia reconocible en el paisaje recorrido por la vía que comunica los municipios. Más que visitar un destino específico, el viajero de la ruta lechera busca experimentar el paisaje ofrecido por la región del altiplano del norte. Al recorrer, inevitablemente hace una lectura inconsciente de este paisaje, de sus calidades visuales, de sus trayectos y paradas paisajeras, inclusive de la experiencia de los alimentos tradicionales de la región. Es posible pues, hablar de un conjunto de rasgos asociados al lugar, que terminan por consolidar una nítida identidad paisajera de la región.

A primera vista podría pensarse que el paisaje lechero es percibido por el visitante como un paisaje natural, dada la dominancia del color verde sobre los elementos construidos que se presentan con una baja densidad. La idea que el viajero tiene de la naturaleza está relacionada a la matriz de colinas cubiertas de pastos para el ganado lechero. Desde la disciplina del paisaje, ésta tipología encaja realmente en la definición de paisaje cultural, debido a la marcada acción antrópica sobre un territorio natural; no con intervenciones duras como edificios y ciudades, sino a través de elementos que, a pesar de ser blandos y verdes, son artificiales. Tales como las plantaciones forestales extensivas alrededor de cuerpos de agua artificiales, o el monocultivo de pastos para el alimento del ganado que conforma un hecho visualmente dominante. La identidad de éste y de cualquier otro paisaje cultural es compleja, se construye no solamente a través de la relación de los elementos entre sí, sino primordialmente con la manera como los efectos de la acción humana se superponen o entrelazan con el medio primigenio (Aponte, 2003). En el caso del paisaje lechero puede leerse una construcción humana a partir de "recursos verdes" sobre una base natural, donde las coberturas correspondientes al ecosistema natural original han sido substituidas. Este paisaje resultante influye fuertemente en el comportamiento y el carácter de sus gentes.

"Desde Santa Rosa de Osos, que domina una extensión desolada de una capa empobrecida y agrietada, escasamente se ve un árbol en cualquier dirección". James J. Parsons, 1949.

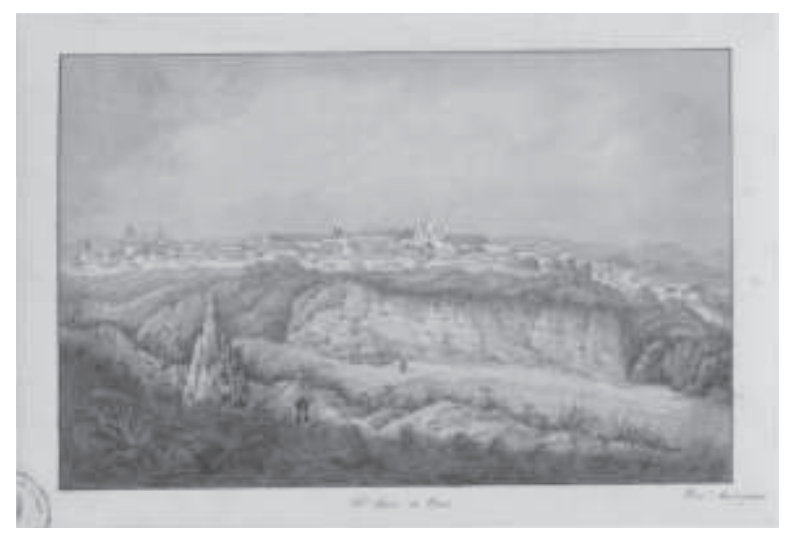

Figura 3. En la Comisión Corográfica de 1852 Henry Price dio cuenta del poblado de Santa Rosa de Osos, asentada en lo alto de una meseta donde ya se observaban las perturbaciones sobre las geoformas como consecuencia de las explotaciones mineras de la colonia. Fuente: Biblioteca Nacional de Colombia. 
Al reflexionar sobre este lugar y sobre el imaginario colectivo que se ha construido alrededor de él surgen algunas preguntas: ¿Cómo se ha conformado la identidad del paisaje lechero? ¿Cuáles son los elementos tangibles e intangibles que conforman la identidad y que permiten identificar este paisaje? ¿Qué relación-nexo existe entre el individuo del norte antioqueño y el paisaje que él mismo ha contribuido a conformar?

Es usual referirse al paisaje lechero en función de su fenosistema; es decir, desde el conjunto de características que pueden percibirse a través de los sentidos, especialmente la vista. Se asocian estas y no otras características diferentes, y se asumen como la identidad actual de este paisaje. Se desconoce, por ejemplo, cual fue la imagen de este altiplano en el pasado, cuando se identificaba con el ecosistema primigenio de bosque andino. Las primeras imágenes pictóricas de este lugar, como las acuarelas realizadas por el paisajista inglés Henry Price para la Comisión Corográfica en 1852, muestran un paisaje ya modificado no solo en cobertura, sino también en relieve. Actualmente el término paisaje lechero no suele asociarse con los relictos de bosque andino o con la importante aptitud hídrica del paisaje, sino con la matriz de pastos salpicada de parches de otras coberturas, en menor proporción y ocurrencia. La imagen de éste y de cualquier paisaje cultural no es estática y permanente; como ya se expresó, es el producto de la constante transformación y desgaste de una estructura natural, en este caso el desmonte del bosque andino aprovechado de diferentes maneras en el tiempo: extracción de árboles maderables para leña y construcción, producción minera, explotaciones hidroeléctricas, cultivos, y actualmente el cultivo extenso de pastos para la rotación de ganado de leche con las consecuencias erosivas sobre la calidad del suelo y demás componentes de la base natural.

El paisaje descrito, igual que cualquier otro paisaje cultural, es producto de sucesivas intervenciones y actividades del ser humano en el espacio. El estado de un paisaje cultural, y particularmente el estado de su sistema natural, expresa el orden cultural impuesto sobre el lugar, o desarrollado a partir de los recursos que el mismo territorio brinda. En el ejercicio de observación y evaluación visual del paisaje lechero se detectan notables perturbaciones en las geoformas, el suelo, el sistema hídrico y las coberturas vegetales naturales. El ecosistema de bosque andino se ha reducido a una mínima expresión; el patrón de aprovechamiento de este paisaje indica la búsqueda del máximo lucro económico con un mínimo de conservación del ecosistema natural, una extensa y creciente matriz de pastos en oposición a un bosque andino, como consecuencia reducido a relictos. La imagen que se va construyendo a partir de la transformación de la base natural para el aprovechamiento, sea económico o de cualquier tipo, contribuye a conformar una nueva identidad de este paisaje cultural.

La imagen del paisaje lechero no es estática, sino producto de las transformaciones efectuadas por las sucesivas generaciones que lo han habitado, sus modos de pensar, sentir y aprovechar los recursos de acuerdo a las necesidades de su tiempo. Lo que hoy se puede denominar paisaje cultural lechero no ha tenido siempre esta misma condición. Durante las primeras exploraciones del norte de Antioquia esta región fue colonizada rápidamente por la desordenada y desenfrenada minería del oro, que inició con el desmonte del bosque andino y el aprovechamiento de los recursos hídricos. Los asentamientos posteriores continuaron con el avance sobre el bosque para obtener leña, maderas para construcción y para despejar nuevos terrenos con fines agrícolas y pecuarios (Parsons, 1950). Hasta la primera mitad del siglo XX este territorio estaba ocupado por pequeños y medianos poseedores de tierras dedicados a la agricultura como fuente de subsistencia, mientras que la lechería desempeñaba un papel complementario y secundario en la economía familiar. El desmonte del bosque andino ha sido, en todos los períodos, una práctica característica del proceder del habitante o tenedor de la tierra. Deforestar el bosque andino y transformarlo en potreros, no solamente manifestaba o marcaba propiedad sobre la tierra, sino que permitía comprender visualmente la 
extensión de las posesiones a la vez que revelaba la aptitud para ganadería o agricultura, y prometía un ingreso monetario. Hacia la segunda mitad de siglo XX la lechería encontró en las colinas deforestadas una base apta para la masificación de la lechería; terrenos deforestados y "limpios" de bosque, propicios para la siembra masiva de pastos, y un abundante recurso hídrico disponible que permitía prescindir del riego para la propagación y sostenimiento. A partir de la década de 1960 coinciden la masificación de los cultivos de pasto para lechería, y el aprovechamiento del recurso hídrico para los proyectos hidroeléctricos y la ocupación de las colinas circundantes con plantaciones forestales de coníferas maderables y comerciables. En un período muy corto de tiempo, menos de medio siglo, el paisaje lechero consolida significativamente la imagen y la identidad visual que hoy se puede reconocer como paisaje cultural lechero.

La percepción que se tiene del paisaje en la ruta lechera está directamente condicionada por la experiencia de atravesar el territorio por la carretera que recorre la región; el viajero atraviesa el territorio en vehículo por una vía ondulante de numerosas curvas y escasas rectas, la cual revela una secuencia de visuales cambiantes pero con cierta homogeneidad en toda la región. En estos recorridos vehiculares, sea por placer o por necesidad, el viajero atraviesa paisajes donde los pastos ocupados con ganado son la escena visualmente dominante; le siguen en relevancia elementos subordinados, como cultivos de papa, zanahoria y tomate de árbol, cercos arborizados con especies foráneas, casas campesinas, marraneras, paradores de carretera y acequias que surcan las hondonadas y pantanos. Se observan algunos elementos singulares y potentes como los característicos cuerpos de agua de la región: el Río Grande y la represa con sus orillas cubiertas de pineras. Cabe preguntarse ¿Qué sucedería si este paisaje estuviera compuesto exclusivamente por pastos y no existiera la diversidad actual de elementos reconocibles visualmente? ¿Qué sería de este paisaje sin una población campesina organizada

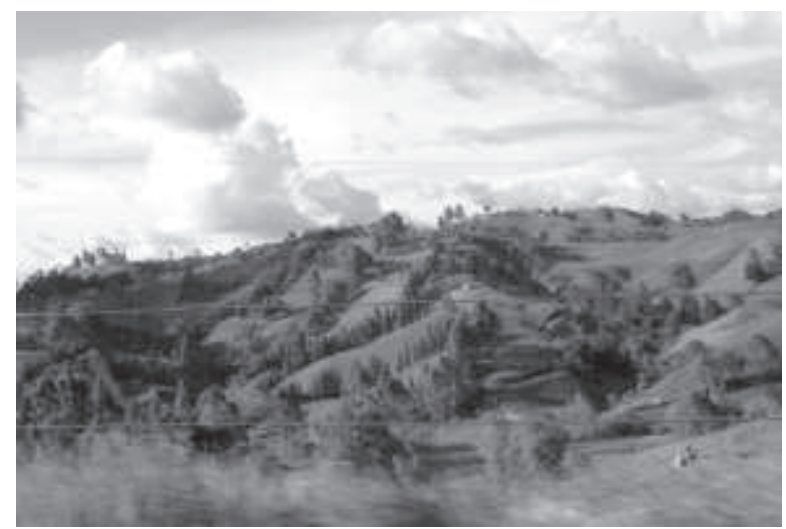

Figura 4. Paisaje de Carretera: colinas ondulantes cubiertas por pastos arbolados que experimenta el viajero en la ruta de la leche a su paso por el municipio de Entrerríos, popularmente denominado: La Suiza colombiana. Fuente: Archivo del autor.

alrededor de la lechería? ¿Podría hablarse de un paisaje cultural lechero o recibiría este paisaje otra denominación? ¿Tendría este paisaje los mismos atractivos y beneficios? Seguramente cambiaría la denominación a proponer en la medida en que fueran diferentes no solo el ecosistema natural y el aprovechamiento; una organización social en el espacio diferente a la actual, con otras prácticas en el paisaje seguramente alteraría la imagen percibida, y finalmente sería otra diferente la identidad del paisaje de este lugar. Si bien la lechería es uno de los rasgos más potentes en este paisaje, no sería posible hablar de tal paisaje cultural en ausencia de esta, o ante una situación en que la lechería fuera el componente exclusivo; a lo que se le puede llamar paisaje lechero no es únicamente una capa o atributo visual sino el conjunto de relaciones y proporciones que pueden percibirse e identificarse visualmente como conjunto.

En el paisaje lechero pueden identificarse como actores sociales determinantes los habitantes dedicados a la economía lechera, junto con las organizaciones asociativas alrededor de la industria lechera; también se han identificado moradores dedicados a otras actividades agrícolas y pecuarias, También se identifican como actores importantes los visitantes esporádicos quienes encuentran el sistema productivo como 
un elemento atractivo en el paisaje. A pesar de ostentar una intensidad turística menor que la identificada en otras regiones de Antioquia como Suroeste y Oriente, el aprovechamiento turístico es esencial en la definición del paisaje cultural lechero. En ninguno de estos actores sociales se reconoce un interés contundente por la conservación del ecosistema del bosque andino, su biota y recursos hídricos asociados. Las prácticas positivas de cuidado del paisaje y de su base natural son atípicas y escasas, se pueden encontrar excepcionalmente en algunos habitantes de la ruralidad dedicados a la agricultura a pequeña escala o a los acueductos veredales. Estas iniciativas de cuidado y conservación son ínfimas, si se comparan con las cifras de producción de leche o los kilómetros de extensión en pastos; no corresponden a la atención que debería recibir la base natural a la luz del equilibrio social, ambiental y económico de la región, teniendo en cuenta que se viven tiempos en los cuales el cambio climático tiene efectos cada vez menos predecibles.

\section{Vacíos y ausencias en el paisaje lechero}

"Cuando mi papá llegó aquí todo esto hasta la orilla del río era monte. Mire donde está la casa; la podría haber construido más hacia el frente, pero era tanto y tan alto el monte que no había manera de darse cuenta de dónde estaba parado".

León Ángel Monsalve, habitante de la Vereda La Muñoz, Santa Rosa de Osos.

Vemos desaparecer de nuestro espacio vivencial objetos, hechos e imágenes que apreciábamos en etapas anteriores de nuestras vidas o que nos proporcionaron alegría y les dieron sabor y albergue a momentos importantes de nuestra evolución (Aponte, 2003). Como grupo social nos resulta imposible apreciar aquello que desapareció de un paisaje. Lo paradójico es que también son constructores de la identidad aquellos faltantes:

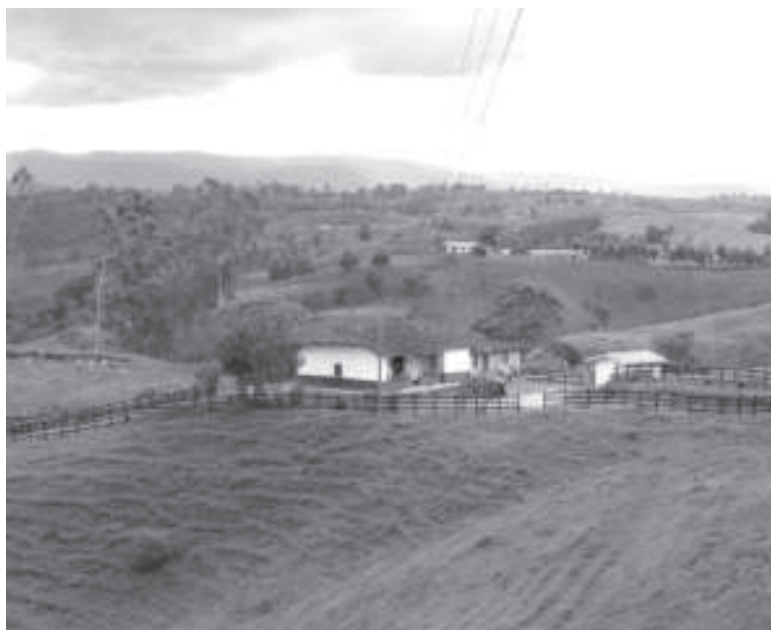

Figura 5. Casa campesina lechera en la vereda La Muñoz en medio de extensos monocultivos de pasto para ganado lechero en Santa Rosa de Osos. Fuente: Archivo del autor.

los bosques, las especies vegetales o animales, los cuerpos de agua vistas por otras generaciones. El recuerdo y la nostalgia son elementos presentes en las narraciones orales de los habitantes del paisaje lechero; sus habitantes recuerdan los elementos perdidos del paisaje en relación a una imagen o ecosistema, pero también a las historias de vida de sus antepasados en el lugar.

En la vereda La Muñoz, a orillas del Río Grande, entre Entrerríos y Santa Rosa de Osos, los hijos de una familia se refieren a la ausencia del padre lo mismo que a la ausencia de bosques, huertos, caminos que se movieron o hitos arquitectónicos demolidos. Los faltantes constituyen la identidad del lugar tanto como los elementos visibles. Los elementos naturales ausentes o intangibles en el ecosistema del bosque andino son igualmente importantes para la identidad del paisaje actual. Inclusive, la ausencia del bosque andino a pesar de la poca renta que representa para los propietarios de la tierra es para los habitantes una de sus mayores señales de identidad; los moradores se reconocen en el aprovechamiento pecuario y en la plantación de pastos, más que en el desuso que encuentran en el monte, dado su bajo valor comercial. En este paisaje una de las más importantes marcas de la personalidad del lugar es la ausencia: el vacío. No 
solo simbólicamente sino visualmente, el vacío es uno de los elementos visuales dominantes tangible en los extensos potreros de pastos para alimento del ganado, desprovistos de otras coberturas vegetales más complejas.

Más que extranjerismos podemos hablar de modos, modismos -en este caso industrialismosque alteran el paisaje y que son traídos de afuera. Esta región es responsable del abastecimiento de derivados lácteos a escalas local, regional, nacional; abastece inclusive un mercado internacional. La leche o el quesito industrializados se distribuyen local y nacionalmente, mientras que productos como el queso blanco se despachan hacia los Estados Unidos. La aspiración de ser una tierra útil y productiva ha traído grandes desbalances ecológicos que se reflejan en la pérdida casi total de la biodiversidad; la producción lechera y el consumo masificado de sus derivados comparten la mayor parte de la responsabilidad en el proceso de extinción del ecosistema natural de esta región biogeográfica. La pérdida de biodiversidad sumada al cambio climático se han convertido en amenaza para la ganadería de leche; los pastos se ven amenazados por la aparición de agentes bióticos como insectos y hongos que ascienden del piso térmico templado y se extienden al encontrarse con una matriz ininterrumpida de pastos sin barreras biológicas. Ante estos hechos el campesino busca aumentar la productividad de sus tierras, se ve obligado a incrementar el uso de agroquímicos, y a colonizar parches de bosque y de rastrojo con nuevos pastos; el resultado es un mayor deterioro de la calidad del suelo y el agua que van perdiendo su aptitud para el aprovechamiento conjunto, tanto para fines productivos como contemplativos.

\section{Cultura e identidad paisajística en la ruta lechera}

Percibir, apreciar, analizar y conocer la naturaleza de los lugares son condición para la concreción de una identidad, pues es necesario conocer y comprender el propio entorno para apropiárselo y finalmente llegar a identificarse con él (Aponte, 2003). Lo nítidamente percibido en el paisaje lechero es aquello construido por el hombre, aquello que es productivo. Lo no-productivo, los relictos de bosque por ejemplo, pasan desapercibidos y son muy poco conocidos por moradores y visitantes. Son una excepción los gestores del recurso hídrico, los líderes de los acueductos veredales y unos pocos habitantes que reconocen el alto valor que tienen los bosques nativos para la sobrevivencia en el lugar (Corantioquia, 2012). La identidad colectiva y la cultura predominante de la región lechera están asociados en gran medida a la matriz de pastos.

El paisaje en general funciona como un gran sistema de memoria para la retención de la historia y de los ideales de un grupo. (Aponte, 2003 citando a Lynch, 1960). En este sentido, las festividades colectivas locales conocidas en Antioquia como Fiestas del Pueblo se realizan en cada municipio con un matiz diferente y se nombran de acuerdo a los rasgos identitarios más relevantes de cada lugar. En la construcción de la identidad festiva un pueblo reconoce y legitima sus valores más representativos y establece una marca local que lo identifica ante sí mismo y ante los visitantes. Esta suerte de cultura oficial y hegemónica suele recurrir a tradiciones, productos, lugares o personajes. En el caso de los municipios de la región lechera la identidad festiva se ha construido a partir de elementos paisajísticos presentes en el lenguaje utilizado para nombrar las fiestas. Se celebran Fiestas de la Leche en San Pedro de los Milagros, Fiestas del Paisaje en Entrerríos, Fiestas del Atardecer en Santa Rosa de Osos, Fiestas del Yarumo en Yarumal y Fiestas de San Isidro Labrador, asociadas en general con el contexto rural. Todos estos municipios reconocen y se apropian de alguna forma de algún elemento característico del paisaje del paisaje lechero de tierra fría y lo vinculan a la noción de Cultura, con mayúscula, aquella que es dominante y hegemónica y es una expresión de ese pueblo que la imagina y la vive.

Sin embargo, hay expresiones del hábitat colectivo que podrían asociarse a aquella cultura, con 


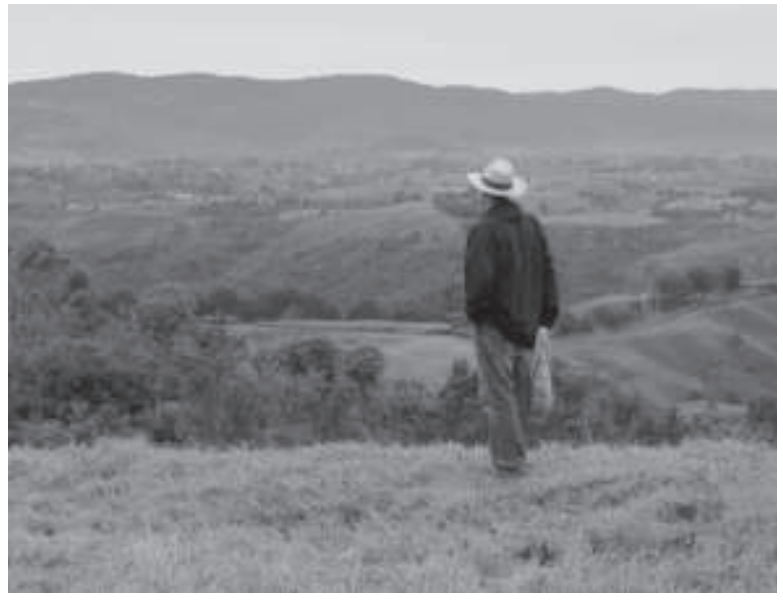

Figura 6. Atardecer en la vereda La Muñoz, Santa Rosa de Osos. Fuente: Archivo del autor.

minúscula, que subyace sin ser apropiada y podría reforzar la Cultura existente. Hay expresiones del paisaje que aún no son vistas o reconocidas por aquel desprevenido perceptor del paisaje (Aponte, 2003). Por costumbre, menosprecio o desconocimiento, algunos estímulos son desconocidos o rechazados como parte de la identidad: valores de la estructura natural como el relieve, los cuerpos naturales y artificiales de agua, los relictos de bosque andino y su mermada pero sorprendente biodiversidad, la flora y la avifauna, en resumen: componentes que no conforman conscientemente la identidad cultural del paisaje lechero. Esta identidad no existe aún. Sería necesario reconocerla y fortalecerla.

El fortalecimiento de esta identidad sería una ardua labor de reconocimiento colectivo en la que podrían valorarse elementos culturales percibidos, como también aquellas capas del pasado que perviven o que subyacen casi invisibles: rutas paisajeras, visuales relevantes, cuerpos de agua naturales y artificiales, sitios de valor histórico, caminos antiguos, toponímicos familiares, acequias y acueductos artesanales, inclusive aquellas brechas coloniales donde se excavo el oro en la colonia y hoy son casi imperceptibles en el paisaje. Deberían reivindicarse los relictos de bosque donde aún habitan cuadros de flora compuestos por orquídeas, bromelias, helechos, anturios y todo un sistema de flora singular asociada al bosque andino que es habitado por una variedad de insectos, aves y pequeños mamíferos a salvaguardar.

Hoy en día ante la amenaza inminente del sobrepastoreo o la reciente megaminería (El Colombiano, 2017) con todas sus consecuencias, sería necesario preguntarse por los valores del paisaje lechero, no desde la nostalgia, sino desde los retos del presente con proyección de futuro; tal vez la mirada paisajista sea una herramienta útil para garantizar la supervivencia y una posible remediación del paisaje cultural lechero que vive una silenciosa pero abrumadora crisis mal llamada ambiental, que realmente es una crisis social que abarca desde la escala individual y va más allá de las fronteras físicas de la ruta de la leche.

Uno de los más importantes antecedentes en el reconocimiento de los valores en los paisajes es el Convenio Europeo del Paisaje, firmado en Florencia, Italia, en 2000. A diferencia de la literatura de UNESCO sobre Paisajes Culturales, este documento hace un llamado al estudio de todo tipo de paisajes, ya que hay paisajes en todas partes (Convenio Europeo del Paisaje, 2000); este documento reivindica la mirada sobre paisajes y valores paisajeros que han sido relegados históricamente: paisajes y valores rurales, ordinarios, degradados y cotidianos, a los que se debe atender. Este documento normativo es uno de los primeros en migrar de una mirada elitista del paisaje (Priore, 1999) (Molina, 2013) a una visión mucho más democrática que pueda ver el paisaje de una manera más amplia, considerando que en cualquier paisaje están en juego dos aspectos simultáneos e indisolubles de la vida del ser humano: identidad y economía. El paisaje conforma el patrimonio natural y cultural, contribuye al bienestar, a la formación de la cultura local y a la consolidación de la identidad, y al mismo tiempo constituye un recurso favorable para la actividad económica; su protección, gestión y ordenación pueden contribuir a la creación de empleo. Ha sido muy poco estudiada la relación entre identidad y economía 
en paisajes culturales como el lechero, y tal vez este sea el momento de preguntarse qué valores y qué cultura en el paisaje lechero deberían fortalecerse para consolidar la identidad y garantizar la economía y subsistencia de sus habitantes.

En esta misma dirección el Observatorio Latinoamericano del Paisaje y la Iniciativa Latinoamericana del Paisaje (LALI, 2000) proponen una aproximación a los paisajes a través de un proceso de sensibilización, formación y educación, identificación y calificación. Reiteradamente se insiste que sensibilidad y sensibilización son un punto de partida para el estudio del paisaje; es necesario que exista un ojo que contemple el paisaje en conjunto $\mathrm{y}$ se genere un sentimiento que lo interprete emocionalmente (Maderuelo, 2005), no es posible estudiar el paisaje sin la aproximación desde los sentidos y la sensibilidad. Este mismo autor plantea la necesidad de partir del supuesto de la sensibilización como paso preliminar al análisis científico. Esta perspectiva, amplia la posibilidad de estudiar el paisaje de una forma mucho más abierta y democrática, no solo por los equipos científicos y especializados, sino por la sociedad civil, los habitantes, en diferentes edades y grados de escolaridad. Posiblemente, en la apertura de la discusión sobre paisajes rurales, extendida de forma mucho más abierta y directa a la población que lo habita, pueda enriquecerse la construcción de la identidad de un paisaje cultural

\section{Discusión}

A continuación se enuncian algunos aspectos que surgen en la discusión sobre el paisaje cultural lechero de tierra fría, la construcción de su identidad en relación a los aspectos naturales y culturales:

Descubrir otros paisajes lecheros. ¿Qué otros paisajes lecheros existen en Antioquia o en Colombia? Es importante reconocerlos a la luz de las zonas de vida (Holdridge, 1996). Hay grandes diferencias entre un paisaje lechero en un ecosistema de montaña, de bosque seco tropical o de sabana. Podrían mencionarse diversas tipologías de paisajes lecheros, de acuerdo a la zona de vida, al tipo de paisaje cultural que se da, cada uno con problemáticas y oportunidades por descubrir.

Reconocer la diversidad de paisajes rurales con un alto componente productivo. Más allá de los paisajes lecheros es posible preguntarse por los paisajes con una alta vocación productiva, sea agrícola o pecuaria. Cada uno con sus particularidades. Es necesario inclusive hablar de paisajes productivos mineros o energéticos que poco han sido abordados en Colombia desde la mirada paisajista.

Valorar los paisajes con las poblaciones que los habitan. ¿Qué valorar en un paisaje productivo? ¿Cuál es la percepción de sus habitantes y visitantes? Sobre todo, ¿Cuál es la percepción colectiva que se tiene de la estructura natural de estos lugares? Serían preguntas que podrían abrirse en los paisajes rurales de carácter productivo para entender qué sucede en aquellos lugares donde el hombre parece haber borrado los rasgos del sistema natural que da soporte a todas sus actividades. Es importante conocer realmente qué es lo que un habitante identifica y con qué se siente identificado, especialmente de la estructura natural, que proporciona el soporte y los servicios para la subsistencia.

Visibilizar lo visible y lo subyacente en un paisaje cultural. De los paisajes culturales con vocación productiva se tiene una percepción dominante de los asuntos visibles, que generalmente constituyen sus más importantes rasgos de identidad. En el caso de los paisajes lecheros el fenosistema o aquello que es mucho más tangible y visible son la matriz de pastos, los parches de plantaciones maderables, el aprovechamiento pecuario y los cuerpos de agua. Lo que subyace y tiene un carácter menos visible, es decir, el criptosistema es un ecosistema de bosque andino, su biodiversidad asociada, el potencial de producción del recurso hídrico y el tipo de relieve. También subyacen casi invisibles, problemáticas como la extinción de las coberturas naturales nativas y su fauna asociada, la contaminación de las aguas por el uso de agro- 
químicos y las transformaciones que desencadena la masificación del uso pecuario en un contexto de cambio climático (Flórez-Malagón, 2008). Cabe preguntarse hoy por aquellos elementos poco visibles que deberían visibilizarse y hacerse conscientes en la colectividad que habita el paisaje cultural.

\section{Diagnosticar el estado de la estructura natural} para la conservación de un paisaje. La conservación del relieve, el cuidado de los suelos, la pertinencia de las coberturas vegetales y la biodiversidad de un paisaje cultural con vocación productiva suelen ser aspectos desatendidos en paisajes rurales donde prima el aprovechamiento y la rentabilidad de la tierra, inclusive sobre el potencial turístico. Es urgente preguntarse hoy por las posibilidades de mitigación de los conflictos que se dan a raíz de la fuerte antropización de la estructura natural; en ese sentido las prácticas positivas de cuidado del paisaje, incipientes en la región, pueden dar algunas pautas y orientar procesos colectivos y a mayor escala de cuidado del paisaje de la región. Es necesario y pertinente comenzar por un análisis de paisaje y diagnóstico del ecosistema natural. Dentro de los métodos más relevantes para el diagnóstico del paisaje cabría implementar métodos visuales de inventario y diagnóstico visual, como el

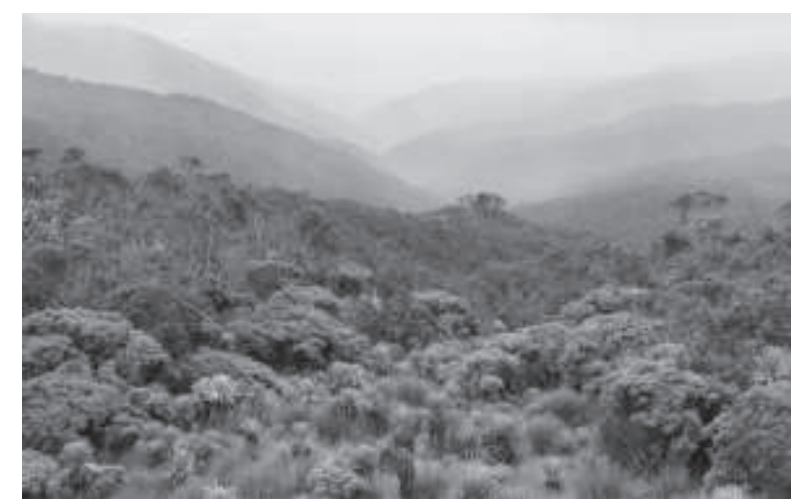

Figura 7. Páramo de Santa Inés, municipio de Belmira. El paisaje de páramo es uno de los más singulares dentro del área de influencia del paisaje cultural lechero. Cumple un papel esencial en la prestación de servicios ecosistémicos y es uno de los más vulnerables en el contexto del cambio climático. Fuente: Archivo del autor. propuesto por Bureau Land Management (Bureau of Land Management, 1984) y su propuesta Visual Resource Management, que establece el inventario de valores visuales del paisaje como ejercicio para diagnosticar el estado de elementos naturales y culturales, desde el suelo y las geoformas, el agua, las coberturas incluyendo asuntos como el color y las modificaciones culturales.

Prácticas de cuidado paisajístico. En todo lugar además de prácticas de orden productivo deben rastrearse aquellas prácticas positivas de cuidado de un paisaje, por incipiente que estas parezcan. Estas prácticas, sean individuales o colectivas podrían dar claves importantes en la construcción de la identidad cultural. En la región lechera es posible detectar en algunos casos aislados de prácticas positivas de cuidado del bosque andino: linderos vivos manejados con rastrojo alto, iniciativas de protección de la fauna silvestre, prácticas agrícolas que protegen el suelo y el agua, conservación de semillas nativas, manejo tradicional de acequias y recursos hídricos, y conservación de saberes tradicionales. Esta serie de eventos positivos, algunos casi extintos no deben despreciarse en la construcción de la identidad cultural.

Formas de aprovechamiento paisajístico. Tratar de entender la naturaleza de los paisajes culturales con vocación productiva no debe excluir en ningún momento dicha actividad económica, ni considerar el paisaje en función exclusiva de la contemplación o el turismo. Estos paisajes deben entenderse como el soporte de las diferentes formas de vida, humana, animal o vegetal en tanto que ofrecen los recursos para subsistir física y espiritualmente. El aprovechamiento paisajístico debe poner en equilibrio los usos culturales sobre el sistema natural y la manera en que estas transformaciones son percibidas por quien habita o visita estos paisajes. Tal vez, una de las claves para el aprovechamiento paisajístico responsable y cuidadoso tenga una base en la mirada de los servicios ecosistémicos que presta un paisaje y el estado de cada uno de ellos: soporte, regulación, abastecimiento y cultura (FAO, 2017). 


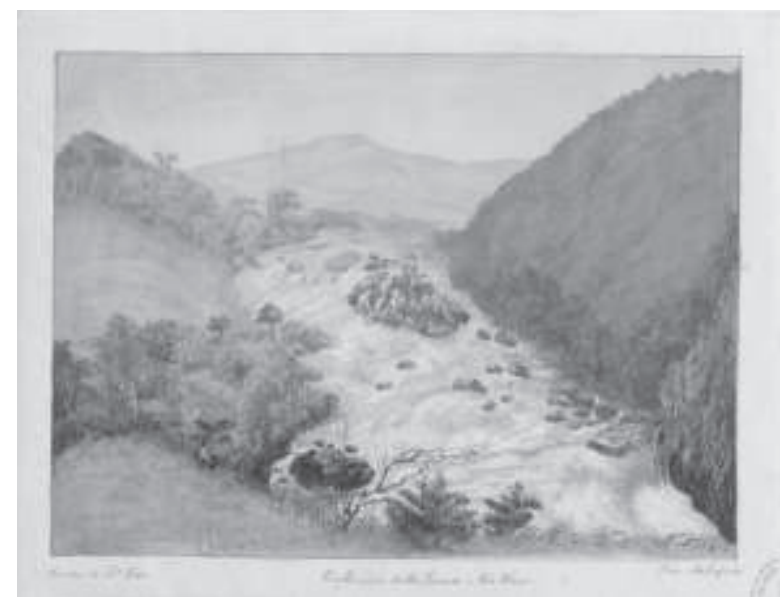

Figura 8. Confluencia de Río Grande y Río Chico. Desde el siglo XIX el paisajista inglés Henry Price documentó la deforestación del bosque andino y el avance de los potreros con pastizales abiertos y extensos. Fuente: Biblioteca Nacional de Colombia.

\section{Conclusiones}

Luego de la discusión sobre el paisaje cultural lechero y la forma como hay una apropiación parcial de los rasgos paisajísticos en la construcción de la identidad colectiva del lugar, se plantean algunas conclusiones que pueden orientar la investigación de manera más amplia.

Además de los paisajes culturales declarados oficialmente es necesario reconocer la diversidad de paisajes productivos en las diferentes zonas biogeográficas colombianas, y entender la multiplicidad de beneficios que estos prestan a sus habitantes y visitantes, e inclusive a quienes no tienen una relación física directa con ellos. Es fundamental pasar de paisajes grandilocuentes con valores excepcionales, universales y con un reconocimiento masivo, a aquellos paisajes cotidianos que tienen una relevancia en la escala local y expresan la diversidad de un país como Colombia que posee variedad de zonas de vida diferentes. Dada esta infinidad de zonas de vida, climas y condiciones geográficas y paisajísticas diferentes es imposible reducir los paisajes culturales a pocas denominaciones, y valdría la pena más bien hablar de las particularidades que hacen especial cada paisaje.

Es necesario asociar lo disociado: el paisaje con vocación productiva y la estructura natural que lo permite, donde el ecosistema original es responsable en gran medida de los servicios obtenidos. En el paisaje cultural lechero estudiado se constató la pérdida casi total del ecosistema natural como un conflicto tangible, pues ha predominado la producción y el lucro económico sobre la conservación y ha sido posible constatar grandes pérdidas en la biodiversidad del ecosistema. Aún más, entre habitantes y visitantes existe un desconocimiento generalizado sobre las implicaciones que tiene el deterioro del ecosistema sobre los sistemas productivos agropecuarios.

En el paisaje cultural lechero se observan intervenciones humanas sobre la base natural que evidencian un conflicto silencioso, poco divulgado y poco comentado inclusive entre los mismos habitantes en relación al agua. El aprovechamiento del paisaje para usos pecuarios y agrícolas entra en conflicto con el potencial hídrico, para consumo humano, para consumo del ganado, riego, e inclusive para el uso hidroeléctrico. Por una parte debido al vertimiento de agroquímicos que deterioran en la calidad del agua, y por otra parte debido al arrastre de partículas sólidas producto de la erosión en los cultivos. La percepción y el reconocimiento de toda la región del paisaje lechero como un importante paisaje productor de agua es bien escasa en un ámbito colectivo, también es muy bajo el reconocimiento del papel que juega el bosque andino en la producción de agua. Más preocupante aún es el escaso conocimiento que existe sobre la pérdida del bosque andino y la incidencia que esto puede traer a los sistemas de producción lechera.

Para la conservación del paisaje cultural lechero y de cualquier paisaje cultural se requiere la identificación, la valoración y el diagnóstico de los recursos y también de las problemáticas paisajísticas, con el fin de garantizar el sostenimiento de estos paisajes en el tiempo para el disfrute de habitantes y visitantes. Es también urgente reconocer 


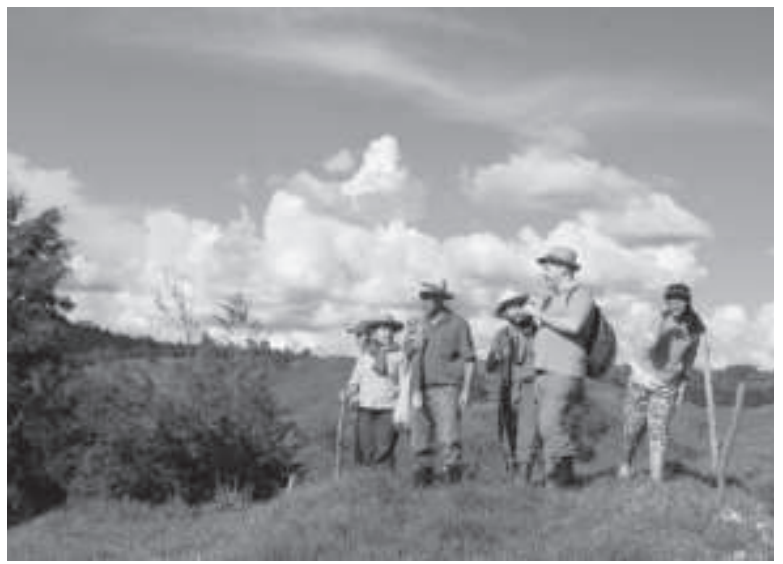

Figura 9. Recorridos paisajeros por el paisaje lechero con habitantes y visitantes de la vereda La Muñoz, Santa Rosa de Osos. Fuente: Archivo del autor.

en estos paisajes el soporte que ofrece el sistema natural a las actividades económicas y culturales que allí ocurren.

Como un paso importante para el cuidado de estos paisajes deben entenderse las percepciones colectivas, la comprensión de los componentes del paisaje, la visibilidad y el reconocimiento que se hace de la estructura natural y su ecosistema primigenio. En el panorama del cambio climático y de la masificación de las agroindustrias es urgente reconocer y proteger la flora nativa del bosque andino, los valores y atributos que le dan soporte a la vida, y que constituyen la base sobre la cual se construye la identidad paisajística y de los habitantes del paisaje cultural lechero.

\section{Bibliografía y Fuentes}

Aponte García, Gloria. (2003). “Paisaje e Identidad Cultural" en Revista Tabula Rasa. N.1: 135-164, enero-diciembre de 2003. Bogotá, Colombia.

Appleton, Jay (1986). The experience of landscape. Hull University Press. Hull, Reino Unido.

Berque, Agustín (2009). El pensamiento paisajero. Editorial Biblioteca Nueva. Madrid, España.

Bureau of Land Management (1984). Visual resource management, Manual 8400 . Department of the Interior. Washington D.C., Estados Unidos.
Colanta (2017). Colanta Institucional. Historia. Disponible en http://www.colanta.com.co/institucional/historia/ Consultado en Mayo 8 de 2017.

El Colombiano (2017). Tres ases de oro con que minería legal de Antioquia brillará en 2017. Disponible en http://www.elcolombiano.com/negocios/ tres-ases-de-oro-con-que-mineria-legal-de-antioquia-brillara-en-2017-YG5594735. Consultado 22 de febrero de 2017. Medellín, Colombia.

Convenio Europeo del Paisaje (2000). Convenio Europeo del Paisaje. Consejo de Europa. Florencia, Italia.

Corantioquia (2012). Marcas de Agua, relatos, memorias y evidencias. Corantioquia. Medellín, Colombia.

Espinal, Sigifredo (1992). Geografía ecológica de Antioquia. Zonas de vida. Universidad Nacional de Colombia. Facultad de Ciencias Agropecuarias. Bogotá, Colombia.

FAO-FEPALE, 2012. Situación de la Lechería en América Latina y el Caribe en 2011, Observatorio de la Cadena Lechera. Oficina Regional de la FAO para América Latina y el Caribe, División de Producción y Sanidad Animal.

FAO (2017). Servicios ecosistémicos y biodiversidad. Disponible en http://www.fao.org/ ecosystem-services-biodiversity/es/ consultado 14 de Agosto de 2016.

Flórez-Malagón, Alberto (2008). El Poder de la carne. Historias de la ganadería en la primera mitad del siglo XX en Colombia. Editorial Pontificia Universidad Javeriana. Bogotá, Colombia.

Holdridge, Leslie (1996). Ecología basada en zonas de vida. Instituto Interamericano de Cooperación para la Agricultura. San José, Costa Rica.

LALI (2012). Iniciativa Latinoamericana de Paisaje. Disponible en https://lali-iniciativa. com consultado 14 de Agosto de 2016. Bogotá, Colombia.

Maderuelo, Javier (2005). El paisaje, génesis de un concepto. Abada Editores. Madrid, España. 
Ministerio de Cultura (2010). Dirección de Patrimonio. Paisaje Cultural Cafetero. Un paisaje cultural productivo en permanente desarrollo. Disponible en http://www.mincultura.gov.co/ areas/patrimonio/publicaciones/Documents/CPaisaje\%20Cultural\%20Cafetero.pdf, consultado 30 de Noviembre de 2016. Bogotá, Colombia.

Parsons, James. (1950). La colonización Antioqueña en el Occidente de Colombia. Imprenta departamental de Antioquia. Medellín, Colombia.

Priore, Ricardo (1999). Derecho al paisaje, Motivaciones sociales y objetivos políticos de la revolución de la aproximación al paisaje en el derecho europeo.

Swanwick, Carys (2002) Landscape Character Assesment Guidance for England and Scotland.
The Countryside Agency. Gloucestershire, Inglaterra.

Molina, César (2013). Una aproximación al paisaje como categoría jurídica y derecho subjetivo en el plan de ordenamiento territorial de Medellín. Opinión Jurídica, Vol 12. №23, pp. 49-66. EneroJunio de 2013/212p. Medellín, Colombia.

UNESCO (2005). Comité Intergubernamental de protección del Patrimonio Mundial cultural y natural. Directrices Prácticas para la aplicación de la Convención del Patrimonio Mundial. París, Francia. Disponible en http://whc.unesco. org/archive/opguide05-es.pdf consultado 30 de noviembre de 2016. 